\title{
Poética literaria y musical de Francisco Gabilondo Soler "Cri-crí»
}

\author{
ÓSCAR ARMANDO GARCÍA \\ Facultad de Filosofía y Letras UNAM
}

Las canciones de Cri-Cri instalan y pueblan un rico paisaje imaginario, integran una de las pocas obras de gran literatura infantil, si no la única, que haya dado la lengua española.

José de la Colina

\section{RESUMEN}

Se trata de una panorámica de la obra musical de Francisco Gabilondo Soler "Cri-Cri", dedicada a una audiencia infantil durante varias décadas del siglo XX en México. Este horizonte permite distinguir sus poéticas musicales y literarias, así como la posibilidad de revalorar a este compositor dentro del ámbito de la literatura y la música hispanoamericana.

Palabras Clave: Canciones infantiles, radiodifusión en México, Francisco Gabilondo Soler "Cri-Cri”, poética musical y literaria

\section{ABSTRACT}

This paper is an overview of the musical work of Francisco Gabilondo Soler 'Cri-Cri ", dedicated to a young audience for decades of the twentieth century in Mexico. This perspective distinguishes his musical and literary poetic as well as the possibility to revalue this composer in the field of literature and Latin American music.

Keywords: Nursery rhimes, broadcasting in México, Francisco Gabilondo Soler "Cri-Cri", musical and literary poetic.

Las primeras experiencias musicales que recuerdo surgieron de las bocinas del tocadiscos y de los diferentes aparatos radiofónicos que convivían en diferentes sitios de la casa. La cocina, la sala, alguna recámara, tenían estos artilugios con su respectiva oquedad de donde surgían palabras, música, dramas, chistes y cuentos de terror. La capacidad de magia de estas bocinas me hacían creer que el disco negro que mi padre depositaba dentro de un enorme mueble de madera era capaz de activar a un ejército de pequeños duendes que habitaban dentro de la inmensa bocina Hi-Fi cuando ejecutaban (lo supe años después) la introducción del Ballet Gayaneb de Khachaturian. ¿Quiénes y cómo eran esos seres que se escondían en tan curiosos aparatos? Años después también supe que esos duendes eran músicos sentados ante un atril; mi padre me llevó a un concierto sinfónico y me quitó de tajo la ilusión de mis duendes, pero a la par me despertó la pasión por la música.

Mi abuela también tenía su radio, junto a la máquina de coser Singer. Confieso que en muchos momentos establecimos un pacto armónico mientras la acompañaba en su
Óscar Armando García

Doctor en Historia del Arte por la UNAM, maestro en Historia por la Universidad Católica de Lovaina, Bélgica y licenciado en Literatura Dramática y Teatro por la UNAM. Es profesor de los cursos dedicados al teatro mexicano, iberoamericano y medieval en la Facultad de Filosofía y Letras de la UNAM y en los posgrados en Letras e Historia del Arte de la misma universidad; ha sido también profesor de la Escuela Nacional de Arte Teatral del INBA, de la Universidad Iberoamericana y profesor invitado del Institut de Teatre de Barcelona, Universidad de Perpignan, Francia y del posgrado en Artes Escénicas de la Universidad Veracruzana. Investigador Nivel I del SNI, director fundador del Centro de Investigaciones Escénicas de Yucatán (CINEY) del Instituto de Cultura de Yucatán, Presidente de la Asociación Mexicana de Investigación Teatral AMIT (2005-2009). Sus ejes principales de investigación han sido el espacio de representación teatral en la Nueva España, la capilla abierta en los procesos de evangelización y las escenificaciones urbanas, aunque también se ha interesado en las representaciones teatrales populares y la dramaturgia latinoamericana. Poética literaria y musical de
Francisco Gabilondo Soler
«Cri-cri»"

ÓSCAR ARMANDO GARCÍA 
La trascendencia y popularidad de Cri-Cri no se ve reflejada en trabajos, ensayos o estudios sobre el tema. Las fuentes bibliográficas más bien son escazas, casi todas orientadas a la anécdota o a la compilación de su obra. Destacan dos trabajos fundamentales: Elvira García, De lunas garapiñadas (1982) y más recientemente la tesis de licenciatura en Historia de Esther Cuatzon Mora, "En otro tiempo mientras estabas no sé dónde..." Francisco Gabilondo Soler CriCri 1934-1961 (2004).

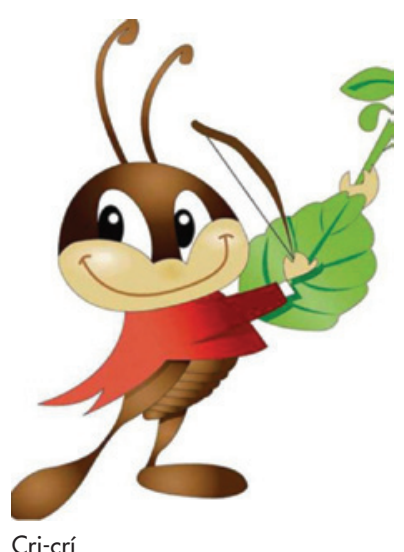

Cri-crí

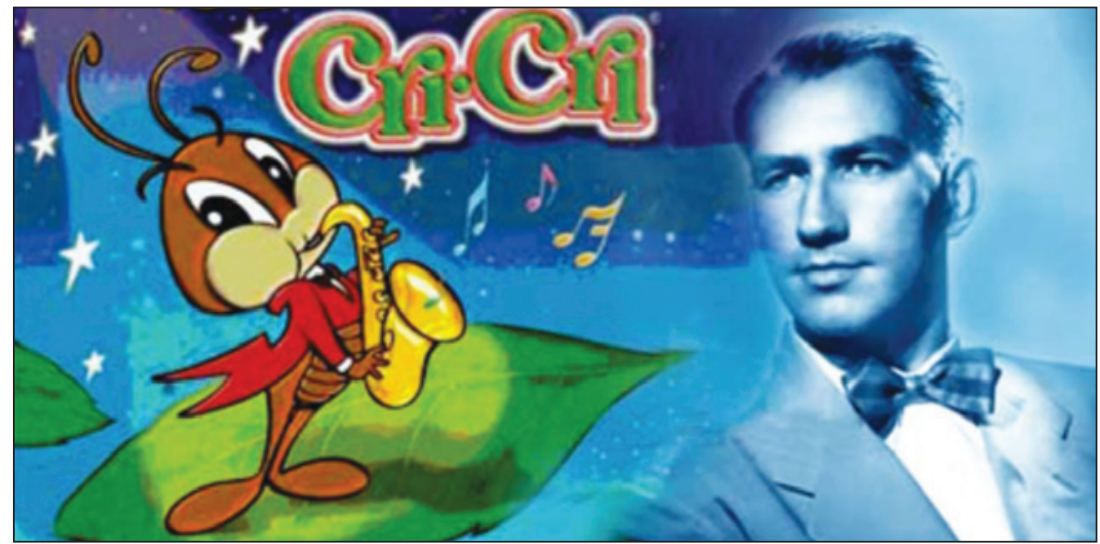

Francisco Gabilondo Soler Cri-crí
Poética literaria y musical de Francisco Gabilondo Soler «Cri-crí»

ÓSCAR ARMANDO GARCÍA costura: no chistar mientras ella escuchaba la emisión de Agustín Lara o mientras se transmitía una radionovela cubana. En moacongojada, lo que para mí siempre fue un misterio: ¿lloraba por el triste destino de los personajes («la pobre Charito») o por alguna pena propia? Y todo por causa de la radio.

Cuando entré a la etapa escolar, la marca para saber si seríamos puntuales a la entrada del colegio era el breve programa de Cri-Cri que se transmitía a las 7:30 de la mañana en la programación de esa época (1964-66). Nuestro previo paso musical imaginario de todos los días hacia el colegio iba acompañado de estas canciones que nunca dejamos de disfrutar.

Hablar de Cri-Cri (como lo constatan la mayoría de las referencias encontradas ${ }^{1}$ ) nos obliga a hacerlo siempre desde una experiencia personal, desde nuestra propia biografía. De esta dimensión fue, es y sigue siendo la trascendencia de la música de este singular personaje.

El reto principal de este ensayo es poder comunicar con palabras el prodigioso mundo musical del compositor mexicano Francisco Gabilondo Soler. ¿Cómo transmitir al lector este panorama, esta inusual poética que marcó mentos, llegaba a llorar de manera discreta y

sus primeras melodías para derivar, posteriormente, en los juegos y en coplas donde comienza también el supremo ejercicio de la narrativa. La sociabilización del niño ha tenido, desde tiempos inmemoriales, y como valioso instrumento de comunicación, a las rondas, cantos, romances e historias de mentiras y de nunca acabar.

México cuenta con una amplia y rica tradición musical infantil, con evidentes herencias indígenas e hispanas. En el prólogo a la Lírica infantil de México, el pedagogo asturiano Luis Santullano comenta cómo «la transmisión de la lírica infantil desde España a la tierra mexicana y a otras tierras de América, (...) pronto adquirió carta de naturaleza y ensanchó sus manifestaciones en virtud de los estímulos del medio ambiente, físico y social.» (7)

Vicente T. Mendoza, autor de esta antología, también destaca una de las principales influencias en la lírica infantil mexicana:

Heredados estos cantos de la cultura hispánica, responden a la sensibilidad de los peninsulares que con mayor abundancia han influido a México desde tiempos de la conquista: asturianos, castellanos, gallegos, andaluces y extremeños, enriquecida esta sensibilidad con los diversos mestizajes producidos en nuestro país; (11)

Por lo pronto anotamos aquí un pensamiento de José de la Colina, quien hace una aseveración de principio atrevida, pero que bien puede retomarse para otro estudio sobre el tema: ¿existe realmente una tradición de literatura infantil en el mundo hispano?

Nuestra literatura, al margen del anónimo y magnífico cancionero folclórico hispano e hispanoamericano, no poseen equivalentes de los cuentos de Andersen y Perrault. (...) el hermoso Platero y yo de Juan Ramón Jiménez habla a la niñez, no desde ella; (19-20)

En este tenor, es importante entonces rescatar la rica producción de cancionero infantil que existe en América Latina, desarrollada sustancialmente durante el siglo XX a través y a partir de la generación de música en los medios de comunicación. Sin duda, es en este siglo cuando observamos uno de los fenómenos culturales y sociales más trascendentes de comunicación: la radiodifusión. 
Este proceso tecnológico permitió que se invadiera el espacio íntimo de los hogares en aquello que, con anterioridad, requería un contacto directo con su emisor en otro sitio o en otro soporte. Periodismo, teatro, literatura, música, eventos deportivos y eventos políticos y sociales ingresaron, a través de un micrófono, a un mundo sonoro que se transfiguraba desde un aparato que podía activar frecuencias en una bocina, para así inundar un espacio clave dentro de sus actividades cotidianas. Esta bocina, en sí misma, sintetizaba voces, música e ideas, que a la vez eran escuchadas en el transcurso de una jornada.

Las voces se activaron en la recuperación del conflicto humano a través de las radionovelas. El teatro y la narrativa dejaron la escena física y las páginas de los libros para transformarse en diálogos sonoros, en un novedoso recurso donde se incorporaron virtuosamente al narrador, a los sonidos ambientales y a la música incidental.

El formato del teatro de revista se adaptó en emisiones radiofónicas donde participaban cómicos, músicos y cantantes. El periodismo se acopló a la radio en el formato de los noticieros y el discurso político también tuvo en la radio un espacio privilegiado de difusión: de la plataforma del mitin a la palestra sonora. También se transmitió el evento deportivo narrado por virtuosos locutores que podían volcar emotivamente el acto del estadio en imágenes sonoras, recuperadas atentamente por el «espectador» radiofónico.

Gracias a todo ello, la radiodifusión (desde sus inicios hasta la fecha) se sigue consolidando como un bastión seguro de comunicación inmediata, ahora inclusive transmitido por las vías internautas.

Es en este contexto donde podemos distinguir la figura de Francisco Gabilondo Soler, compositor musical quien, desde 1934, se incorporó a la radiodifusión mexicana, dedicado de lleno a una audiencia infantil y que, hasta ahora, su creación sigue teniendo repercusión en las nuevas generaciones a través de Cri-Crí y de todos los personajes de sus canciones.

\section{Vida y obra}

Francisco Gabilondo Soler nació en 1904, originario de la ciudad veracruzana de Oriza- ba, al pie del gigantesco volcán Citlaltépetl, hijo de Tiburcio Gabilondo, de origen vasco, y de Emilia Soler, de familia catalana-malagueña. Su educación musical la hereda de sus padres y de una tía, pero las escazas biografías manifiestan sus particulares y disímbolos intereses dirigidos hacia otras actividades como la tauromaquia, la astronomía, la música, la marina y el boxeo. De 1941 a 1944 decide hacer un viaje en un barco carguero a Sudamérica y habita en la ciudad de Buenos Aires. Retorna a México para continuar su carrera y la composición de canciones infantiles. Falleció en la ciudad de Texcoco el 14 de diciembre de 1990 a la edad de 83 años.

Desde muy joven se desplaza desde Orizaba a la Ciudad de México para probar suerte profesional, lo que lo lleva a la radiodifusora $\mathrm{XEW}$, donde ofrece su talento como compositor de boleros románticos y canciones cómicas. Su entrada a los estudios de radio fue en una emisión patrocinada por la Lotería Nacional, donde pronto fue denominado «El guasón del teclado» por su virtuosismo en la interpretación en el piano y su enorme capacidad para improvisar melodías de su juguetona inspiración.

Pronto también corroboró que su intención por componer canciones se veía siempre ensombrecida ante autores como

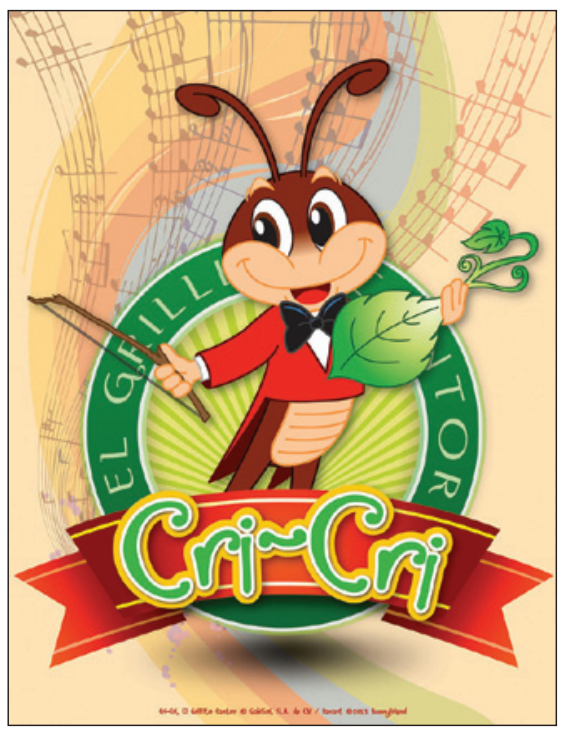
Agustín Lara o Guty Cárdenas, grandes jerarcas del género. Fue el productor Othón Vélez quien le sugirió que cambiara de giro temático y Rosario Patiño (su primera esposa) le ofreció la idea de que se encargara de un programa dirigido específicamente a los niños, donde pudiera improvisar cuentos y canciones. Gabilondo Soler aceptó con ciertas reticencias y su primera transmisión fue el lunes 14 de octubre de 1934 a la una de la tarde. En un par de semanas de ensayo y error, Gabilondo Soler elaboró y propuso que el personaje guía del programa fuera "CriCri, el Grillito Cantor». ¿De dónde surgió el nombre? Francisco Gabilondo lo explica con sus propias palabras en una entrevista:

Entonces yo pensé: «Bueno, ¿cómo se podría llamar un grillito?» y como hace muchos años a los niños

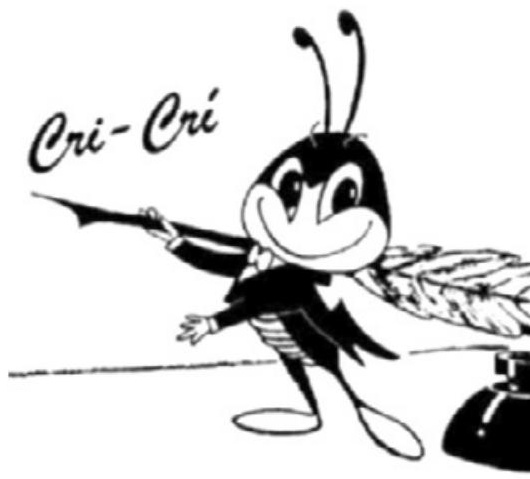
. 
Todas las letras de las canciones que se citarán en el ensayo se encuentran en Cri-Crí: canciones completas de Francisco Gabilondo Soler (2001).

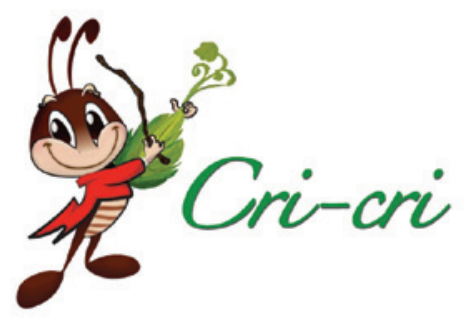

Poética literaria y musical de Francisco Gabilondo Soler «Cri-crí»

ÓSCAR ARMANDO GARCÍA

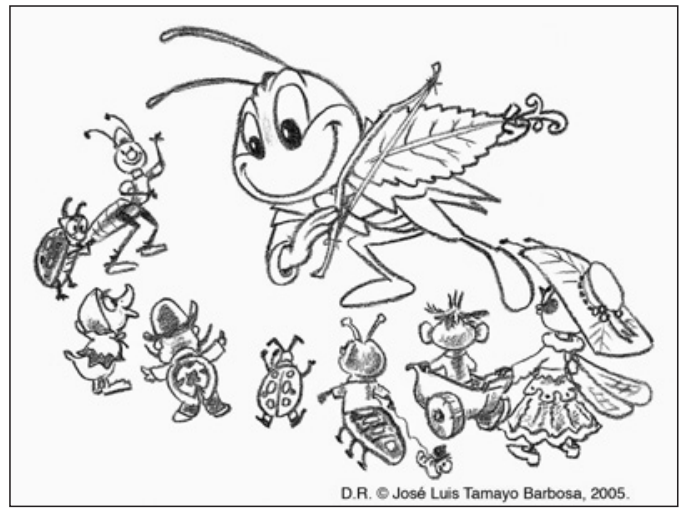

nos enseñaban en la escuela francés así como ahora enseñan el inglés, yo sabía que para designar el grillo en francés había dos palabras. Una es grillon, que es la usual, y la otra es cri-cri. Así de sencillo (Granados Chaparro, 109).

A partir de entonces se consolida la pletórica carrera de Gabilondo Soler, quien llega a componer aproximadamente 215 canciones dedicadas a los niños.

\section{Contexto cultural y educativo}

Si tomamos la fecha de 1934 nos encontramos ante una marca significativa para la cultura mexicana. Ese año se inaugura el Palacio de las Bellas Artes en la Ciudad de México como parte de la adecuación urbana de un modernismo que fue interrumpido por la lucha revolucionaria. También inicia el periodo presidencial del general Lázaro Cárdenas; su visión de la educación socialista se establece como prioridad en las escuelas de nivel básico y se enaltecen los valores nacionalistas a través de la música, las artes plásticas y la danza.

Desde los proyectos educativos de Álvaro Obregón se estableció que los escolares dedicaran un número importante de horas de su instrucción al aprendizaje y disfrute de canciones mexicanas, (...) Aparte, en el taller de canto se aprendía un amplio repertorio de canciones regionales o en lenguas indígenas, que se interpretaban antes de comenzar la jornada escolar (García 2010:73).

Como lo hemos comentado, la radio se convirtió desde esa década en el principal difusor de noticias, música y cultura a nivel nacional. El país tuvo en este medio un punto de encuentro y convocatoria de gran potencia. Tan sólo recordemos en este contexto las palabras del general Cárdenas en el momento de anunciar la Expropiación Petrolera el 18 de marzo de 1938, o bien la declaratoria de guerra por parte del presidente Ávila Camacho el 28 de mayo de 1942. Para la Segunda Guerra Mundial, la radio fue vital para poder seguir paso a paso los acontecimientos que afectaban los diversos rincones del mapa europeo.

\section{Las breves historias}

Francisco Gabilondo toma los micrófonos a partir de un reto creativo sin precedentes: ofrecer a una audiencia infantil un espacio de imaginación a través de breves historias narradas y cantadas, con personajes fantásticos, que en gran medida hacían referencia a la vida cotidiana, en alternancia animales, humanos y objetos.

Las variadas estructuras anecdóticas y métricas de sus canciones hacen posible una agrupación temática que se distinguen a lo largo de sus composiciones más célebres. En un lúcido artículo, el poeta Luis Ignacio Helguera comenta:

Primer mérito evidente de la música de Cri-Cri es entretener a los niños (y a los adultos que saben volver a ser niños) sin tareas, ni sermones, ni moralinas, ni varitas pedagógicas. El Grillo que sólo cursó hasta sexto de primaria sabe transmitir, sin esfuerzos innecesarios contenidos morales, sociales, pedagógicos, además de $-\mathrm{y}$ sobre todo - musicales. Esto, que es un logro de la imaginación literaria y la imaginación musical puras, implica una diversificación de registros de pequeños géneros (Helguera 35).

Gabilondo Soler comenzó su producción con pequeñas historias entresacadas de lecturas clásicas y de su propia imaginación. Así, una de sus primeras canciones que surgieron en los estudios de la XEW fue Bombon I, una fantasía basada sustancialmente en la idea de la casa de galletas en Hansel y Gretel, (Granados Chaparro 110) aunque en esta canción se elabora tan sólo la historia alrededor de un Rey de Chocolate (con nariz de cacahuate) que trata de conquistar el amor de la princesa Caramelo. Cochinitos dormilones podría haber rescatado la leyenda de los tres cerditos que construyen diferentes casas para ser derribadas por un lobo feroz, sin embargo Gabilondo transfigura esta fábula en una 
tierna situación sobre los deseos que cada uno de los cerditos tiene mientras duermen. Otro ejemplo, La cacería, permite seguir la historia simple del Conejo Blas, cazador furtivo, que defiende a sus borregos del asecho del lobo.

Dos canciones descriptivas se encuentran en el ámbito de la familia del compositor: $E l$ llavero y Di por qué, las cuales tienen como personaje central a la abuela; en la primera es quien resguarda con celo los objetos más preciados de su vida en un ropero, por lo que el interlocutor le solicita el llavero para poder abrir ese fascinante tesoro de recuerdos. La segunda es una completa definición de la vejez desde la visión de un niño que no comprende la actitud de su abuela, sus limitaciones físicas, sus silencios y sus recuerdos permanentes, generando un verdadero poema sobre la naturaleza de los abuelos:
Di por qué dime abuelita,
$\mathrm{Di}$ ¿por qué eres viejita?
Di ¿por qué sobre las camas
ya no te gusta brincar?
Di ¿por qué, usas los lentes?
Di ¿por qué, no tienes dientes?
Di ¿por qué, son tus cabellos
como la espuma del mar?
Micifuz, siempre está
junto al calor, igual que tú.
Di por qué, frente al ropero
donde hay, tantos retratos,
di ¿por qué, lloras a ratos?
Dime abuelita, ¿por qué??

\section{Canciones pedagógicas}

Un ciclo importante de las canciones de Cri-Crí serán las de características pedagógicas. Es paradójico que las instituciones educativas hayan tratado de manera marginal la producción de Gabilondo Soler por considerarlo producto de la mercadotecnia, sin embargo pronto sus melodías serán materiales obligados en las aulas de preescolar y primaria ${ }^{2}$. Rondas como El coro de las chicharritas maneja de manera impecable los elementos necesarios para la dinámica propia de la onomatopeya y la coreografía:

¡Trrrrrrrrrrrrrr! ¡Trrrrrrrrrrrrrr!
Las noches de verano
son luminosas y tibiecitas,
cantan las chicharritas:
¡lara lara lara lá!
¡Trrrrrrrrrrrr! ¡Trrrrrrrrrrrrr!
Cuando la luna sale
por los copetes de las milpitas,
zumban las chicharritas:
¡lara lara lara lá!

Pero la que más llama la atención es una de sus canciones más populares y emblemáticas: El chorrito la cual, además de sus virtudes musicales e imaginativas, proporciona una temprana lección de los estados físicos del agua en dos versos que el compositor añadió posteriormente a su difusión inicial en la radio del tema principal que dice: «Allá en la fuente/ había un chorrito / se hacía grandote/ se hacía chiquito». El texto fue enriquecido entonces con los siguientes versos:

La gota de agua que da la nube como regalo para la flor, en vapor se desvanece cuando se levanta el sol; y nuevamente al cielo sube hasta la nube que la soltó.

(...)

En el paisaje siempre nevado acurrucado sobre el volcán, hay millones de gotitas convertidas en cristal.

En el invierno la nieve crece, en el verano la funde el sol.

La presencia de la hormiguita en la canción complementa la interacción de los perso-
3 En la publicación Cri-Cri: canciones completas se consigna en la Cronología que en 1958 «La Secretaría de Educación Pública prohíbe el uso de las canciones de Cri-Cri en las escuelas preescolares por recomendación de Luis Sandi y Rosaura Zapata».

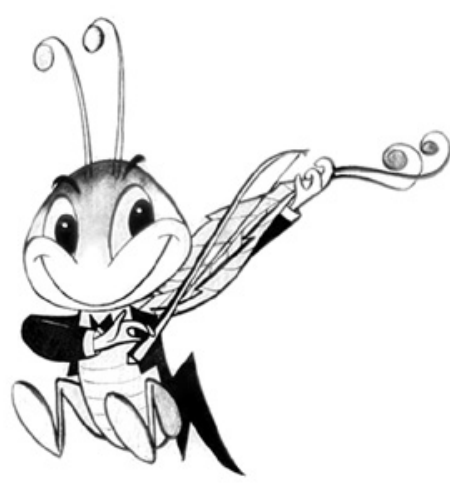

Poética literaria y musical de Francisco Gabilondo Soler "Cri-crí"

ÓSCAR ARMANDO GARCÍA 


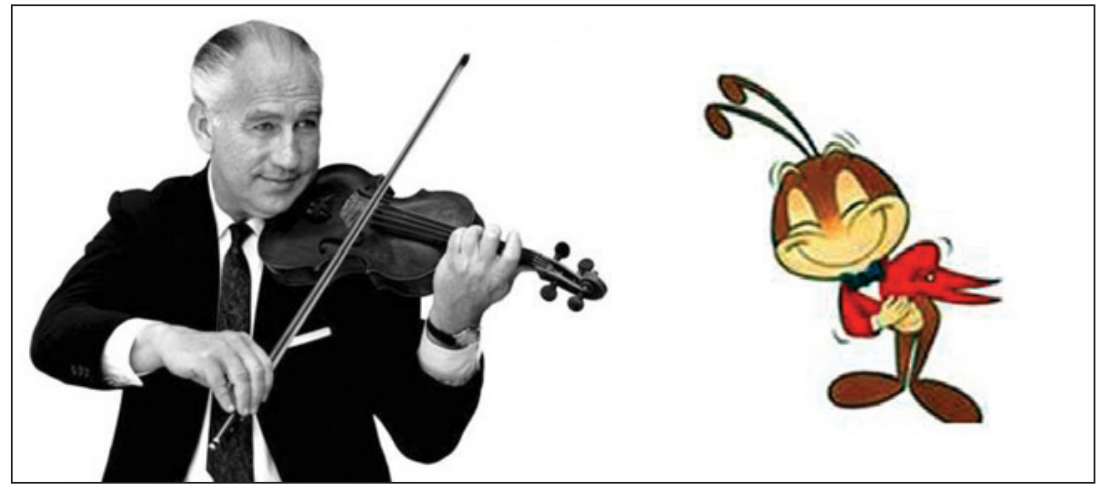

najes: el Chorrito en la fuente y la Hormiguita que padece el intenso calor. El panorama de la breve anécdota hace que los niños repliquen en graciosa coreografía las andanzas de estos personajes.

Pero también La marcha de las letras se une a este ciclo educativo para que, a partir de esta marcha, los niños comiencen a identificar la forma de cada una de las vocales.
Primero verás
que pasa la ' $A$ '
con sus dos patitas
muy abiertas al marchar.
Ahí viene la 'E'
alzando los pies,
el palo de en medio
es más chico como ves.
Aquí está la 'I',
le sigue la ' $\mathrm{O}$ '
una es flaca y la otra
gorda porque ya comió.
Y luego hasta atrás
llegó la 'U',
como la cuerda
con que siempre saltas tú.

Esta canción también es probablemente de las más difundidas de Cri-Crí y se complementa con Caminito de la escuela, donde Gabilondo recrea graciosamente el primer día de cursos de los críos, o el Solfeo de los patos, así como La escuela de los Perritos, que recurre al sistema del silabario en boca de los personajes:

Si pongo una $\mathrm{M}$, después una $\mathrm{A}$, «Cri-crí» y luego las repito, dirá MAMÁ.

Se rieron los perritos de tal facilidad $\mathrm{y}$ todos juntos deletrearon:

Au, áu, áu, áu, áu!

Otro ejemplo, en parte cuento, pero también como canción de moraleja está $L a$ Cocorica

Salió la gallina, salió a pasear con sus diez pollitos por el corral.

Doña Cocorica les hace ver

lo que todo pollo debe saber:

- Aprendan primero que aquí en el corral

su padre el Gallo es la autoridad;

a diario, temprano, se oye su voz,

y es porque ordena que salga el Sol.

Doña Cocorica se encariñó

con los diez pollitos que Dios le dio, apenas salieron del cascarón y ya todos saben bien la lección - Ahora pollitos tendrán que buscar algún gusanito para merendar. Y al verlos rascando tras una lombriz, la dulce Gallina es muy feliz.

(...)

-Escuchen pollitos, no deben correr pues son pequeñitos, se pueden caer. A los pollos tontos se los comerán los pícaros gatos o el gavilán.

\section{De ambientes y situaciones}

Dentro de la producción de Cri-Cri encontramos varias canciones que nos remiten a situaciones diversas, ambientadas magistralmente por la música escrita para cada una de ellas. El primer ejemplo es La orquesta de animales, la cual recrea una sesión de trabajo de una orquesta integrada por la vaca, el gato, león, changos, etcétera, quienes cada uno es descrito con su instrumento específico. Destaca, entre muchas creaciones, la canción dedicada a la Muñeca fea, breve historia de una muñeca abandonada en un desván que de momento se entristece por su situación, pero un ratón se encarga de valorar a sus verdaderos amigos, es decir, aquellos con quienes convive: la araña, el plumero, el recogedor y el viejo veliz. Otro ejemplo es la canción de $E l$ gato de barrio, donde Gabilondo Soler ubica al escucha en la vida cotidiana de un barrio de la Ciudad de México; música y giros lingüísticos juegan en armonía para presentarnos esta lúcida ambientación del México de mediados del siglo XX. 


\section{La negritud}

Varios son los ejemplos que encontramos alrededor de la negritud en la producción de Cri-Cri. El tema tiene varias fuentes: la experiencia musical que el compositor tuvo desde niño en su natal Orizaba, los viajes emprendidos a Estados Unidos y a Sudamérica y la integración de la cultura africana en tierras mexicanas. Tres son las canciones más célebres de esta temática: Negrito Sandía, la Negrita Cucurumbé y El negrito bailarín. La primera canción narra, en sabroso ritmo de rumba, la historia de un coqueto niño que, cuando crece y aprende a hablar, "salió más deslenguado que un perico de arrabal». La segunda es una interesante reflexión sobre los rescoldos racistas con los que aún convivimos en México, es decir, la situación de una niña jarocha que acude a la playa tropical para ver a la luna, a la espuma del mar y a las conchas y verificar si ellas pueden cambia el color de su piel. Aparece del mar «un pescado con bombín» que invita a la negrita a asumir su color de piel como una característica propia de su belleza. La tercera es una de las más redondas creaciones literario-musical de Cri-Cri, en la cual se describe a un juguete de cuerda de principios del siglo XX: un negrito bailarín de tap, con una vestimenta típica de la época (bastón, bombín y un clavel en el ojal).

Las tres canciones tienen una correspondencia musical admirable con respecto a los personajes y siguen teniendo una amplia aceptación entre los escuchas, fuera de apreciaciones «políticamente correctas» sobre la negritud. Recordemos que para la sociedad mexicana la influencia africana se encuentra imbricada en su cotidiano a través de su historia, sin embargo aún está presente una incertidumbre sobre sus orígenes, mezcla de orgullo nacional y desprecio por el marginado. Las intenciones de la Negrita Cucurumbé no dejan aún de habitar los deseos de definición étnica de la sociedad mexicana.

\section{Las otredades}

La obra de Gabilondo Soler explora generosamente varios contextos culturales de otras latitudes. De esta manera incluye en su repertorio canciones descriptivas sobre personajes de varias nacionalidades. Con un gran dominio musical y con gracejadas literarias para proponer pasajes en otros idiomas (reales

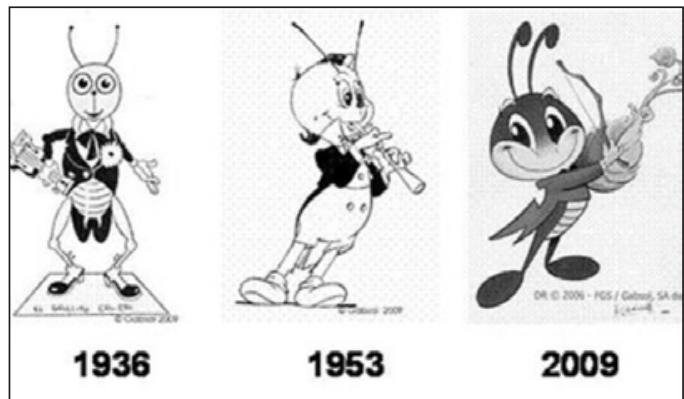

o inventados), Gabilondo presenta un panorama realizado con viñetas de todo el mundo.

Ché Araña encabeza esta lista como una canción descriptiva de un viejo barril desvencijado a manera de bar arrabalero de Buenos Aires donde se dan cita varios insectos y un gato bandoneonista que ven bailar tango a Ché Araña de manera virtuosa. La canción está resuelta magistralmente en el ritmo y está integrada al repertorio de los mejores tangos hechos en América.

Presento dos ejemplos orientales: Chong $K i F u$ y Jorobita. La primera es una canción chinesca que relata un breve cuento donde un chinito pide libertad pues ha vivido siglos en un jarrón por mal hablado y desobediente, quien exclama: "iYan-tse-amo-oua-ting-ipong-chong-kí».

La segunda es la divertida historia del camello Jorobita quien, a punto de desfallecer en el desierto, un gran Sultán, lo invita a a comer un Ice Cream y a vivir en su palacio. En un principio la narración inicia con este verso:
Por el desierto
un pobre camello pasó,
ofustalmut ala
Iba sediento, cansado,
muerto de calor,
marfajet marajha

Rusiana, a su vez, es una canción sencilla, donde un oso siberiano va cantando por la estepa con su balalaika la siguiente melodía:
Hola, hola, ulalá,
Ponka, pinshki, pas, petruska,
Rosca, rosca, ulalá.
Hola, hola, ulalá,
Ochichornia, zanahoria,
calabaza ulalá.

Varias canciones de Cri-Crí tienen ritmos o motivos españoles, como es el caso de esta
Poética literaria y musical de Francisco Gabilondo Soler «Cri-crí»

ÓSCAR ARMANDO GARCÍA 
ingeniosa propuesta sobre el aprendizaje de la letra «J» en La Jota de la Jota:

En la mitad de la clase me reprendió el profesor cuando dije que la jota es un bailable español. ¡Valiente maleta! grito hacia mí, la jota es la letra después de la i.

¡Qué noticia! ¡Tiene gracia!

Pues a poco no voy a saber que mi abuela la bailaba, y por cierto mi abuelo también.

Sin embargo, dos canciones completan este rubro del mundo extranjero. Mi amigo Hans es la aventura de un niño alemán que su tío no deja jugar, ya que tiene qué estudiar con una férrea disciplina germana.

Pues siempre a toda hora
lo pone a estudiar
la física, la química
la historia natural.
Pues quiere que el sobrino
sea sobrenatural,
sabiendo cinco idiomas
y hasta cálculo integral.
Clavado en los libros
el chico suspira,
bosteza, se estira
ipobre Hans!

La última canción de este ciclo es tal vez de las más escuchadas y reproducidas escénicamente por los niños mexicanos; se trata de El ratón vaquero, una deliciosa historia que ha captado siempre la atención no solamente por la destreza musical y literaria, sino porque se trata, dentro de la cultura mexicana, de las pocas canciones donde se logra un triunfo patriota: encarcelar a un forajido norteamericano. La pequeña historia pasa de la cotidiana situación de un ratón atrapado en una ratonera a la posibilidad de recrear a un ratón norteamericano encarcelado que, en un momento dado, exclama:

What the heck in this house

Poética literaria y musical de Francisco Gabilondo Soler «Cri-crí»

ÓSCAR ARMANDO GARCÍA for a manly Cowboy Mouse

Hello you! Let me out!

And don't catch me like a trout.
A lo que contesta Cri-Cri:

Conque sí, ya se ve, que no estás a gusto ahí, y aunque hables inglés no te dejaré salir.

\section{Economía, política y sociedad}

La obra de Gabilondo Soler tiene puntos sobresalientes de reflexión económica y política, singularmente una de sus primeras canciones que compuso: La Patita, quien va al mercado y no encuentra nada que le alcance porque el marido Pato es un vago y perezoso que no aporta sustento a la familia. En una de las estrofas de la canción, este drama se sintetiza y finaliza de la siguiente manera:

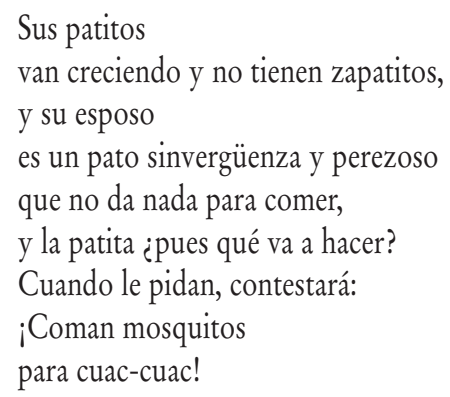

El Comal y la Olla es otro ejemplo de crítica a la convivencia social, a través del diálogo que desarrollan una olla de barro y un comal; durante la conversación se generan una serie de reclamos sobre cuál de los dos objetos es el más valioso y sobresaliente, sin darse cuenta que su labor no puede desarrollarse más allá del ámbito de la cocina. Destacamos finalmente la canción El Jicote Aguamielero, donde se narra un amor imposible entre la Reina de las Abejas y el Jicote aguamielero. En unas líneas, el Jicote, ante la negativa de la Reina, subraya el papel que tienen las conquistas de la democracia, como puede ser la Constitución, sobre todo ante la actitud francamente absolutista de la Reina.

Leí que éramos iguales 'asegún' la Constitución, la sociedad sin clases la creí, pero ya 'vio' que no.

(...)

Adiós reinecita hermosa, jay!, que me trató tan mal. Pero 'asegún' las leyes del país aquí todos son igual. 
Y el Jicote Aguamielero, con bigotes de aguacero, rezumbando regresó a su maguey; sin rubores en la frente porque ultimadamente a la sombra de las pencas es el Rey.

\section{Los géneros musicales}

La destreza musical de Gabilondo Soler le permitió resolver sus pequeñas historias dentro de ritmos apropiados para cada una de ellas. Así entonces, dentro de su amplísima producción, escuchamos fox-trot, danza, vals, tango, huaracha, danzón, canción mexicana, barcarola, habanera, jota, ritmos con remembranza oriental y tirolesa. Como indica José Antonio Alcaráz: «...porque en cada canción Cri-Crí inventa, propone, descubre, fantasea, opera como acicate para la aventura propia, más allá de cuanto establece cualquiera de los relatos musicales que ha emprendido» (22).

Si nos centramos en la actividad musical de Francisco Gabilondo Soler estaremos ante una figura fuera de serie, inclusive si lo comparamos con las capacidades de repertorio rítmico o temático de sus contemporáneos Agustín «Guty» Cárdenas, Agustín Lara, María Greever, Ignacio Fernández Esperón o Alberto Domínguez, por citar algunos. La tarea emprendida desde 1934 hasta 1941 de componer una canción semanal para la emisión radiofónica de Cri-Cri forjó un reto constante de creatividad para poder atrapar la atención de la audiencia infantil. El paso de los años no desgastó esta creatividad, todo lo contrario, permaneció constante en un músico autodidacta que se permitía toda clase de licencias poéticas en sus creaciones desde la simple diversión del compositor.

Esta relación entre texto, métrica musical y carácter crea una preciosa unidad orgánica, notoria al momento mismo de la audición. El oyente, a quien no conciernen tales consideraciones técnicas, resiente, sin embargo, sus efectos, mismos que proporcionan una coherencia particular al transcurso mientras la escucha (Alcaráz 21).

Es posible entonces reconocer que en la amplia y sólida producción de Francisco Gabilondo Soler se puede encontrar una poética literaria y musical sui géneris, que al paso del tiempo podría distinguirse, como adecuada-

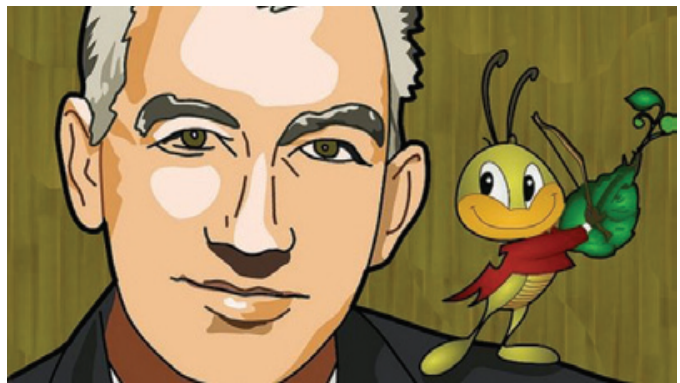

mente propone el crítico José de la Colina, como una de las figuras más prominentes de la literatura infantil en habla hispana, junto con las producciones literarias de Gabriela Mistral, Violeta Parra o bien el trabajo de composición musical que en su momento desarrolló en Argentina María Elena Walsh y de manera más reciente Luis Pescetti, así como la obra de los hermanos Rincón, cuyas creaciones merecen un estudio aparte.

La música y literatura de Cri-Crí permitió que se generara una voz cómplice en los niños mexicanos a través de la radio (en su momento) y en los demás medios que surgieron posteriormente. Gracias a la radio, por ejemplo, las mujeres tuvieron voz y opinión secreta a través de las letras de los boleros, como lo consigna lúcidamente Pável Granados en su artículo «Otras voces, otros ámbitos» (2005). En sintonía con esta reflexión, los niños seguramente también tuvieron en la obra de Gabilondo Soler una compañía, una potente activación de la imaginación y una voz que hicieron propia, a través de múltiples historias, personajes y situaciones que siempre tendrán un referente directo en la vida cotidiana. Varias de sus canciones han trascendido al habla coloquial como sincero reconocimiento al artista que supo condensar parte de la vida en festivas canciones. Esta es sin duda la comprobación más contundente de las aportaciones de un creador que gestó una poética y una huella indeleble en la música y la literatura mexicana del siglo XX.

\section{Bibliografía}

Alcaráz, José Antonio. Cri-Crí: el mensajero de la alegría, Veracruz: Instituto Veracruzano de Cultura, 1998.

Colina, José de la. «Prólogo» en Cri-Crí: canciones completas de Francisco Gabilondo Soler, México: Clío, 2001.
Poética literaria y musical de Francisco Gabilondo Soler "Cri-crí»

ÓSCAR ARMANDO GARCÍA 
Cuatzon Mora, Esther. "En otro tiempo cuando estabas no sé dónde...»: Francisco Gabilondo Soler Cri-Cri 1934-1961, Puebla: Facultad de Filosofía y Letras BUAP, 2004.

Cri-Cri: canciones completas de Francisco Gabilondo Soler. México: Clío, 2001.

García, Elvira. De lunas garapiñadas. CriCri, México: Radio Universidad Nacional Autónoma de México, 1982.

García, Elvira. "¿Quién es el que anduvo aquí?» en Tierra adentro. Días de radio, México: $n^{\circ}$ 137-138, diciembre 2005: 97-99.

García, Óscar Armando. «Cancioneros» en México: doscientos años, ochenta voces, México: Secretaría de la Defensa Nacional, 2010: 71-74.

Granados Chaparro, Pável.»¿Quién es el que anda ahí? Cri-Crí en XEW y otros por- gramas infantiles» en $X E W 70$ años al aire, México: Clío / Sistema Radiópolis, 2000: 107-119.

Granados, Pável. «"Otras voces, otros ámbitos": las voces y las canciones de la radio mexicana» en Tierra adentro. Días de radio, México: $\mathrm{n}^{\circ}$ 137-138, diciembre 2005: 120-126.

Helguera, Luis Ignacio. «Acerca de la música de Cri-Crí» en Cri-Crí: canciones completas de Francisco Gabilondo Soler, México: Clío, 2001: 33-40.

Mendoza, Vicente T. Lírica infantil de México, México: El Colegio de México, 1951.

Tierra adentro. Días de radio, México: ${ }^{\circ} 137-$ 138, diciembre 2005.

Fecha de recepción: 07/07/2015

Fecha de aceptación: 15/10/2015 